\title{
Trading Hours and Price Efficiency: The Case of Hong Kong
}

\author{
Jinghan Cai ${ }^{1}$, Fengyun $\mathrm{Li}^{2 *}$, Xiangyu Lian ${ }^{3}$ \\ ${ }^{1}$ Department of Economics and Finance, University of Scranton, Scranton, USA \\ ${ }^{2}$ School of Finance, Renmin University of China, Beijing, China \\ ${ }^{3}$ Business Development Department, China Development Bank, Beijing, China \\ Email: jinghan.cai@scranton.edu, ^lify@ruc.edu.cn, lianxiangyu@cdb.cn
}

How to cite this paper: Cai, J., Li, F. and Lian, X. (2018) Trading Hours and Price Efficiency: The Case of Hong Kong. Theoretical Economics Letters, 8, 3537-3547. https://doi.org/10.4236/tel.2018.815217

Received: November 1, 2018

Accepted: December 4, 2018

Published: December 7, 2018

Copyright $\odot 2018$ by authors and Scientific Research Publishing Inc. This work is licensed under the Creative Commons Attribution International License (CC BY 4.0).

http://creativecommons.org/licenses/by/4.0/

\begin{abstract}
This paper studies the impact of trading-hour adjustment in Hong Kong Stock market and how this change affects the price efficiency in Hong Kong stock market. We find that the extended trading hours in Hong Kong results in a significantly negative cumulative abnormal return. Also, both the stock price synchronicity and the price delay decrease significantly, which represents the improvement of the price efficiency.
\end{abstract}

\section{Keywords}

Trading Hours, Price Efficiency, Hong Kong Stock Market

\section{Introduction}

On November 23, 2010, the Hong Kong Stock Exchange (HKEx hereinafter) announces to extend the trading hours of the securities and derivatives markets of the HKEx. The trading hours in Hong Kong used to be: 10:30 am to 12:30 am, 2:30 pm to $4 \mathrm{pm}$, with a total of 4 hours of trading time throughout the day. From March 7, 2011 (the first Monday of the month), the trading hours of the HKEx Securities and Derivatives Market changes to: 9:30 am to 12 noon and from 1:30 pm to 4:00 pm, a total of 5 hours of trading time throughout the day. From March 5, 2012 (the first Monday of the month), the trading hours are further revised from 9:30 am to 12 noon and $1 \mathrm{pm}$ to $4 \mathrm{pm}$, and the afternoon trading time is half an hour ahead, a total of 5.5 trading hours.

The Hong Kong Stock Exchange believes that the new trading hours will increase the overlap of trading hours between Hong Kong and the Mainland China stock market, strengthen the price discovery function of the relevant securities in ${ }^{\star}$ Corresponding author. 
the Mainland in the Hong Kong market, and narrow the gap in trading hours between the Hong Kong market and competitors in the region, to strengthen competitiveness. There are three main reasons why the HKEx has announced the extension of trading hours:

1) The opening time of the Hong Kong market will be moved from 10:30 a.m. to 9:30 a.m., which will be consistent with the Shanghai and Shenzhen markets. Hopefully it will help strengthen the linkage between the two markets and facilitate investors to hedge transactions. 2) The total trading time is extended from 4 hours to 5.5 hours, which can increase the daily trading volume and make the trading more active. 3) Before the adjustment, the opening time of the Hong Kong stock market was the latest in Asia, and the trading hours of the whole day were significantly shorter than the average.

In recent years, competition between major global stock exchanges has become increasingly fierce. China's stock market has always attracted a large number of people, with a high liquidity, so there is no obvious competitive pressure. And because the capital market is not fully liberalized, it is not easy for domestic investors to invest in overseas securities. Therefore, China's stock market has never lacked liquidity. However, the liquidity of some other markets is not as good as A-shares in China's stock market. Not surprisingly, they have been trying to improve their competitiveness to attract investors by providing more convenient trading systems, better pricing mechanisms and longer trading hours. In order to realize this goal, Europe and the United States acquire other exchanges to reinforce their strength ${ }^{1}$. The trading hours of these European and American exchanges are relatively long. Generally speaking, the trading hours are all over 6 hours. The US trading time is 6.5 hours, and the trading hours in Germany and the UK are as long as 7.5 hours. In contrast, Asian countries' trading markets have relatively short trading hours, which are basically within 6 hours, so they usually adopt a method of extending trading hours to improve their competitiveness. Major Asian exchanges such as Japan, and Singapore have extended their trading hours in 2011. Currently, the Japanese stock market trades for 6 hours throughout the day, and the Singapore stock market trades for 6.5 hours.

To follow up other markets nearby, the HKEx plans to extend the trading hours from the original 4 hours to 5.5 hours. After adjusting the trading hours, the opening hours of the Hong Kong market in early trading will keep pace with A-shares in China. At the same time, the trading hours of Hong Kong stocks for 5.5 hours per day will fully cover the four-hour trading hours of A-shares. Since Hong Kong is closely related to the financial market in mainland China, and there are a large number of dual-listed firms (i.e., $\mathrm{A}+\mathrm{H}$ shares), it is expected that the adjustment of trading hours will enhance the synchronicity between the

${ }^{1}$ On May 22, 2007, the New York Stock Exchange Group merged with the European Stock Exchange to become the New York Euronext Group; 2007 On May 25th, NASDAQ Stock Market Corporation acquired the Nordic securities dealer Sweden OMX Group to become the world's largest stock exchange company and so on. 
Hong Kong stock market and the Chinese stock market, and improve the price efficiency of the stocks in Hong Kong.

Our paper uses 60 dual-listed companies in both China and Hong Kong stock markets to explore the impact of the trading-hour adjustment. We find that the trading-hour adjustment results in a significant negative cumulative abnormal return for the underlying stocks. The trading volume of the relevant stocks shows no significant change, but the liquidity worsens slightly. Moreover, the stock price synchronicity and the price delay all decrease significantly which represents the improvement of the price efficiency for the stocks in Hong Kong after the extension of trading hours. The results indicate that the adjustment does obtain its original goal.

The rest of the paper is arranged as follows: Section 2 discusses the data and methodology. Section 3 shows the empirical results, and Section 4 concludes.

\section{Data and Methodology}

The stock trading data used in this paper are from Wind.com. Our target is the common stocks in Hong Kong stock market. However, since the change of trading hour in Hong Kong is a market-wide event, there are no readily available control stocks to exclude the possible market-wide noises. Therefore, we use the $\mathrm{A}-\mathrm{H}$ shares as a natural experiment. The so-called A-H shares are dual-listed firms in both China and Hong Kong Stock markets. For a same firm, the shares listed in mainland China is called the A-Shares, while those listed in Hong Kong stock market is called the H-shares. For a same firm, the Hong Kong listed $\mathrm{H}$-shares are subject to the impact of the trading hours change, while the China listed A-shares are not. The A-H stock pair therefore forms a natural experiment to explore the consequence of the trading-hour change reform.

The HKEx announces the trading-hour change on November 23, 2010, and the effective dates for the two adjustments are: March 7, 2011 and March 5, 2012. So for the two events, we use a one-year window before and after March 7, 2011. We choose the dual-listed firms whose IPO dates are no later than October 1, 2009. There are 60 pairs of A-H shares used in our paper.

We examine the following measures in this paper: Cumulative abnormal returns (CAR), trading volume, Amihud illiquidity measure (ILLIQ), $\mathrm{R}^{2}$, and price delays. We now show the measures of ILLIQ, $\mathrm{R}^{2}$, and price delays as follows:

\section{1) Amihud illiquidity measure (ILLIQ)}

Amihud [1] proposes to measure illiquidity by the ratio of absolute stock return to its dollar volume. He argues that this can be interpreted as "the daily price response associated with one dollar of trading volume, thus serving as a rough measure of price impact." One advantage of this ILLIQ is: this measure only needs daily data on returns and volume to calculate, and can be calculated for longer time periods than we have microstructure data for. A larger ILLIQ refers to a large price impact of one dollar invested in the underlying stock, which is an indicator of low liquidity, and vice versa. The follow formula shows the calculation of Amihud illiquidity (ILLIQ). 


$$
I L L I Q_{i, y, d}=\frac{\left|R_{i, y, d}\right|}{V O L D_{i, y, d}}
$$

where $I L L I Q_{i, y, d}$ means the illiquidity measure of stock $i$ in year $y$, date $d$. $R_{i, y, d}$ is stock $i$ s daily return on date $\mathrm{d}$ in year y. $\operatorname{VOL} D_{i, y, d}$ is stock $i$ s daily dollar volume on date $d$ in year $y$. Therefore, the illiquidity measure for stock $i$, in year $y$ is defined as:

$$
\operatorname{ILLI} Q_{i, y}=\frac{1}{D_{i, y}} * \sum_{t=1}^{D_{i, y}} \frac{\left|R_{i, y, d}\right|}{\operatorname{VOLD} D_{i, y, d}}
$$

where $D_{i, y}$ is the number of trading days for stock $i$, in year $y$.

\section{2) Price synchronicity $\left(R^{2}\right)$}

Morck, Yeung and Yu [2] use a novel measure, the price synchonicity, or the $R^{2}$ from a market model to proxy the information inefficiency. They propose that stronger property rights promote informed arbitrage, which capitalizes detailed firm-specific information. Therefore, $R^{2}$ is a measure of inverse price informativesness. This $R^{2}$-based inefficiency measure has gained increasing popularity in recent years and is widely used in various empirical studies of corporate investment and emerging market development, e.g., Wurgler [3], Durnev, et al. [4], Li, Morck and Yang [5], Jin and Myers [6], Morck, Yeung and Yu [7]. In our paper, we use the following steps to estimate the price synchronicity. We first run the following regression:

$$
r_{i t}=\alpha_{i}+\beta_{i} r_{m t}+\varepsilon_{i t}
$$

where $r_{i t}$ is the continuously compounded weekly return of stock $i$ at week $t$. $r_{m t}$ is the continuously compounded weekly return of Shanghai Composite Index (for A shares) and Hang Seng Index (for H-shares) at week $t . \varepsilon_{i t}$ is the error term. $R^{2}$ is the goodness-of-fit for the market model. However, the $R^{2}$ is bounded between -1 and +1 , we therefore follow Morck, Yeung and Yu [2] and extend the codomain of $R^{2}$ to all real numbers by adopting the following log-transformation:

$$
\Psi=\log \left(\frac{R^{2}}{1-R^{2}}\right)
$$

which we use as a measure of price synchronicity. A higher $\Psi$ refers to a lower price efficiency (or higher price inefficiency). The reason why we use weekly return is that, higher frequency returns (e.g., daily returns) suffer from biases such as non-synchronous trading and bid-ask bounces, while lower frequency returns (e.g., monthly returns) tend to lose too much information [8].

\section{3) Price Delay}

Hou and Moskowitz [8] use stock price delay in reflecting market-wide information to measure the extent of market frictions each individual firm encounters. Market frictions include transaction costs, stock illiquidity, and information asymmetry. They find that market frictions associated with lack of investor recognition appear the most responsible for causing price delay. In this 
paper, we adopt their methodology and try to check the trading hour change's impact the price informativeness captured by price delay. The price delay is defined as follows:

$$
r_{i, t}=\alpha_{i}+\beta_{i} R_{m, t}+\sum_{n=1}^{3} \delta_{i}^{(-n)} R_{m, t-n}+\sum_{n=1}^{3} \gamma_{i}^{(-n)} r_{i, t-n}+\varepsilon_{i, t}
$$

where $r_{i, t}$ is stock is continuously compounded return for week $t . r_{m t}$ is the continuously compounded weekly return of Shanghai Composite Index (for A shares) and Hang Seng Index (for H-shares) at week $t, R_{m, t-n}$ is the $n$-week lagged market return, $r_{i, t-n}$ is the $n$-week lagged return for stock $i$. If stock $i$ responds to new information fast enough, the coefficients of the lagged terms $\left(\delta_{i}^{(-n)}\right.$ and $\left.r_{i}^{(-n)}\right)$ will not be different from 0 , and the inclusion of the lagged terms will not significantly increase the explanatory power of the model. The price delay that we adopt in this paper is defined as:

$$
\mathrm{D} 1=1-\frac{R_{\delta_{i}^{(-n)}=0, \gamma_{i}^{(-n)}=0}^{2}}{R^{2}}
$$

D1 is the Price Delay, which captures the component in stock $i$ s return which can be explained by the lagged terms. $R_{\delta_{i}^{(-n)}=0, \gamma_{i}^{(-n)}=0}^{2}$ is the $R$-square for the constrained model, $R^{2}$ is the R-square for the unconstrained model. This price delay measure captures the potential market frictions on the price process of a stock, including incomplete information [9] [10], asymmetric information [11], short-sale constraints [12], among others. A higher price delay refers to a lower price efficiency.

\section{Empirical Results}

\subsection{Cumulative Abnormal Return}

The cumulative abnormal return is calculated using the following model. For the first event, the effective date is March 7, 2011, and we use September 1, 2010 to March 6, 2011 as the estimation window. We further use March 7, 2011 to May 7, 2011 as the post-event window. We then run the following models:

$$
\begin{gathered}
C A R_{i}\left(t_{1}, t_{2}\right)=\sum_{t=t_{1}}^{t_{2}} A R_{i t} \\
A R_{i t}=R_{i t}-\hat{R}_{i t} \\
\hat{R}_{i t}=\hat{\alpha}_{i}+\hat{\beta}_{i} R_{m t}
\end{gathered}
$$

where $R_{i t}$ is the return for stock $i$, where $r_{i t}$ is the continuously compounded weekly return of stock $i$ at week $t . \quad r_{m t}$ is the continuously compounded weekly return of Shanghai Composite Index (for A shares) and Hang Seng Index (for $\mathrm{H}$-shares) at week $t . \varepsilon_{i t}$ is the error term. $\hat{\alpha}_{i}$ and $\hat{\beta}_{i}$ are obtained in the estimation window. The results of the CAR are shown in Figure 1 and Table 1.

In Figure 1 and Table 1, we can see that after 15 trading days, there has been a significantly negative return. This CAR remains negative in the 40 trading days, indicate a negative market reaction. The negative CAR may reflect the 


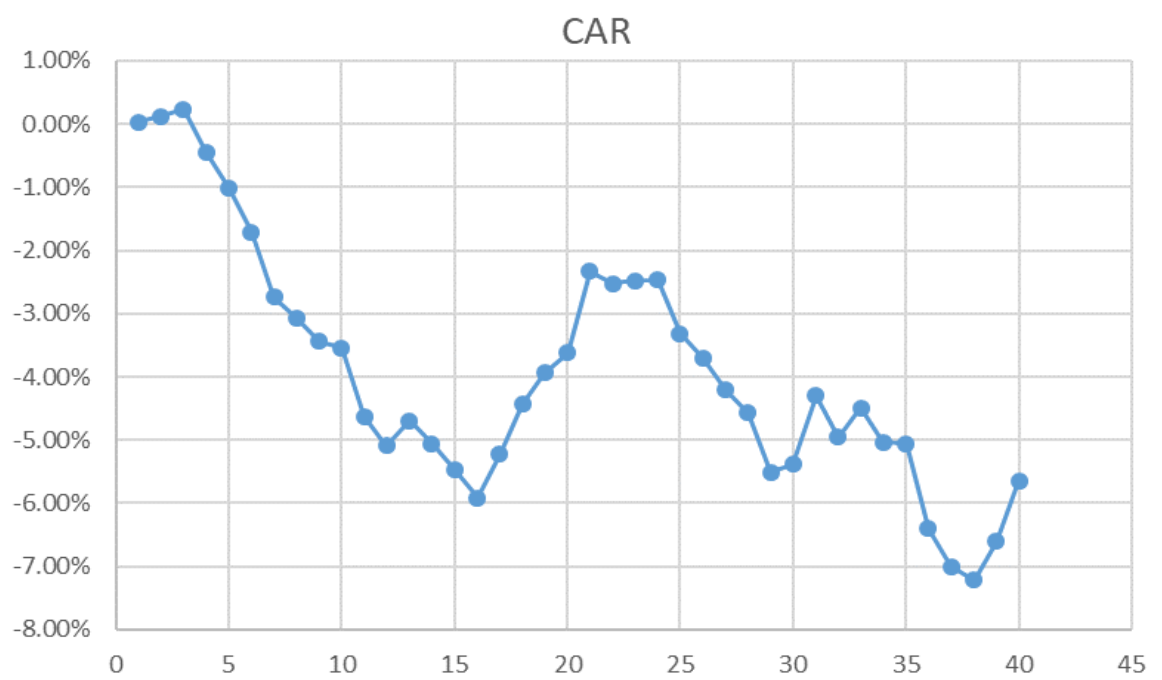

Figure 1. The cumulative abnormal return.

Table 1. The cumulative abnormal return.

\begin{tabular}{ccc}
\hline Window & CAR & t-value \\
\hline$(0,1)$ & $0.03 \%$ & 0.15 \\
$(0,2)$ & $0.13 \%$ & 0.36 \\
$(0,3)$ & $-4.18 \%$ & -5.95 \\
$(0,5)$ & $-1.03 \%$ & -1.98 \\
$(0,8)$ & $-3.06 \%$ & -5.16 \\
$(0,10)$ & $-3.54 \%$ & -5.56 \\
$(0,15)$ & $-5.46 \%$ & -7.51 \\
$(0,20)$ & $-3.62 \%$ & -4.20 \\
$(0,25)$ & $-3.32 \%$ & -3.39 \\
$(0,30)$ & $-5.38 \%$ & -5.04 \\
$(0,35)$ & $-5.06 \%$ & -3.83 \\
$(0,40)$ & $-5.64 \%$ & -3.64 \\
\hline
\end{tabular}

complaints from the industry. It is reported that the reform has been fiercely resisted by some local stockbrokers, who say they need the extended lunch break to meet with clients and conduct research. The brokers have organized a number of last-ditch protests. Local brokers and traders from the city's many smaller brokerage houses are unhappy with the shorter lunch break and say the move favors bigger firms, with more staff and resources, and the negative mood is reflected in the lower CAR.

\subsection{Trading Volume, Liquidity, and Price Efficiency}

This section shows the impact of the trading hour change in HKEx. First, we show the comparative statistics of trading volume, Amihud Illiquidity, R-square 
and price delay for the 60 pairs of dual-listed firms in China and Hong Kong. The results are shown in Table 2.

Table 2 shows that: there is evidence showing that the volume of $\mathrm{H}$-shares increases mildly after the reform. Liquidity worsens after the reform. However, the price efficiency proxied by R-square and price delay improves after the reform. In order to further test this result, we adopt the following difference-in-difference (DID) regression model

$$
y_{i t}=\beta_{0}+\beta_{1} D_{t}+\beta_{2} D_{i}+\gamma D_{t} * D_{i}+\delta_{1} \text { Size }_{i}+\delta_{2} \text { ROA }_{i}+\delta_{3} \text { Leverage }_{i}+e_{i t}
$$

where $y_{i t}$ is the (logged) volume, ILLIQ, $R^{2}$, price delay, which are defined earlier. $D_{t}$ is a dummy variable which equals 1 for post-event window, and 0 for pre-event window. $D_{i}$ is a dummy variable which equals 1 if stock $i$ is a Hong Kong-listed $\mathrm{H}$-share test group, and 0 if stock $i$ is a China-listed A-share control group. The control variables include the logged total market capitalization of stock $i$ (Size), the return on asset for stock $i$ (ROA), and the leverage for stock $i$ in 2011. This DID show the results of the impact from the trading hour change on the H-shares, using the A-shares as the control group. The results are shown in Table 3.

From the results of Table 3 we can see that the trading hour change has no impact on the H-shares, in the sense that the interaction term $D_{t}^{*} D_{i}$ is not significant. The Amihud Illiquidity measure increases significantly after the trading hour change, indicating worsened liquidity. Interestingly, the $R^{2}$ and price delay measures significantly decrease, both indicating improved price efficiency. The results show that the initial intention of HKEx has been obtained: HKEx wishes to extend the trading hours in Hong Kong to be more consistent with Chinese stock market. Therefore, after the trading hour change, more information can be impounded during the trading hours, so that the price efficiency is improved for the H-shares. The decreased $R^{2}$ and price delay show supports to this conclusion.

Table 2. Descriptive statistics. This table shows the descriptive statistics of trading volume, Amihud illiquidity measure, R-square and price delay for the one-year window before and after the first trading hour change date.

\begin{tabular}{cccccccccc}
\hline & \multirow{2}{*}{ Group } & \multicolumn{2}{c}{ Volume $\left(10^{8}\right)$} & \multicolumn{2}{c}{ Illiq $\left(10^{-7}\right)$} & \multicolumn{2}{c}{ R-square } & \multicolumn{2}{c}{ Price delay } \\
\cline { 3 - 9 } Mean & Hre & 0.29 & 0.29 & 2.3 & 0.22 & 0.46 & 0.48 & 0.17 & 0.05 \\
& Post & 0.33 & 0.20 & 13 & 0.40 & 0.31 & 0.44 & 0.08 & 0.04 \\
\multirow{2}{*}{ Median } & Pre & 0.12 & 0.19 & 0.24 & 0.0094 & 0.48 & 0.49 & 0.10 & 0.04 \\
& Post & 0.14 & 0.15 & 0.4 & 0.013 & 0.25 & 0.47 & 0.04 & 0.03 \\
\multirow{2}{*}{ Max } & Pre & 2.8 & 1.3 & 44 & 1.1 & 0.86 & 0.78 & 0.79 & 0.21 \\
& Post & 3.9 & 1.3 & 210 & 2.6 & 0.71 & 0.77 & 0.77 & 0.16 \\
\multirow{4}{*}{ Min } & Pre & 0.004 & 0.022 & 0.0067 & 0.011 & 0.04 & 0.12 & 0.01 & 0.00 \\
& Post & 0.003 & 0.017 & 0.0082 & 0.016 & 0.00 & 0.01 & 0.01 & 0.00 \\
\multirow{2}{*}{ Stdev } & Pre & 0.59 & 0.29 & 6.4 & 0.26 & 0.20 & 0.17 & 0.18 & 0.04 \\
& Post & 0.77 & 0.21 & 40.0 & 0.56 & 0.22 & 0.20 & 0.12 & 0.03 \\
\hline
\end{tabular}


Table 3. Difference-in-difference regression. This table shows the results of the DID regression. we adopt the following difference-in-difference (DID) regression model: $y_{i t}=\beta_{0}+\beta_{1} D_{t}+\beta_{2} D_{i}+\gamma D_{t} * D_{i}+\delta_{1}$ Size $_{i}+\delta_{2} R O A_{i}+\delta_{3}$ Leverage $_{i}+e_{i t}$ where $y_{i t}$ is the (logged) volume, Illiq, R-square, price delay, which are defined earlier. $D_{t}$ is a dummy variable which equals 1 for post-event window, and 0 for pre-event window. $D_{i}$ is a dummy variable which equals 1 if stock $i$ is a Hong Kong-listed H-share test group, and 0 if stock $i$ is a China-listed A-share control group. The control variables include the logged total market capitalization of stock $i$ (Size). The return on asset for stock $i(\mathrm{ROA})$, and the leverage for stock $i$ in 2011 .

\begin{tabular}{cccccccccc}
\hline & \multicolumn{2}{c}{$\ln$ (Volume) } & \multicolumn{2}{c}{ ILLIQ $\left(10^{-6}\right)$} & \multicolumn{2}{c}{$\mathrm{R}^{\wedge} 2$} & \multicolumn{2}{c}{ Price delay } \\
\hline \multirow{2}{*}{$D_{i}$} & $-0.63^{* *}$ & $-0.52^{* *}$ & 0.208 & 0.123 & -0.11 & -0.06 & $0.12^{* *}$ & $0.12^{* *}$ \\
& $(-2.60)$ & $(-3.61)$ & $(0.56)$ & $(0.36)$ & $(-0.57)$ & $(-0.31)$ & $(5.73)$ & $(5.82)$ \\
& & & & & & & & & \\
$D_{t}$ & -0.36 & -0.24 & 0.0183 & -0.153 & -0.33 & -0.21 & -0.01 & -0.01 \\
& $(-1.501)$ & $(-1.63)$ & $(0.05)$ & $(-0.44)$ & $(-1.61)$ & $(-1.18)$ & $(-0.37)$ & $(-0.43)$ \\
$D_{t}^{*} D_{i}$ & 0.27 & 0.32 & $1.06^{*}$ & $1.02^{*}$ & $-0.64^{*}$ & $-0.62^{*}$ & $-0.08^{* *}$ & $-0.08^{* *}$ \\
& $(0.78)$ & $(1.55)$ & $(2.02)$ & $(2.10)$ & $(-2.2)$ & $(-2.44)$ & $(-2.56)$ & $(-2.72)$ \\
Size & & $0.59^{* * *}$ & & $-0.393^{* * *}$ & & $0.28^{* * *}$ & & $-0.02^{* *}$ \\
& & $(18.35)$ & & $(-5.09)$ & & $(7.05)$ & & $(-4.76)$ \\
ROA & & $-0.04^{* * *}$ & & -0.0284 & & 0.016 & & 0.003 \\
& & $(-2.89)$ & & $(-0.79)$ & & $(0.85)$ & & $(1.28)$ \\
Leverage & & 0.09 & & -0.265 & & 0.22 & & -0.02 \\
& & $(0.28)$ & & $(-0.35)$ & & $(0.57)$ & & $(-0.56)$ \\
Con & $16.73^{* *}$ & $13.14^{* *}$ & 0.0216 & $2.86^{* *}$ & -0.09 & $-2.11^{* *}$ & $0.05^{* *}$ & $0.16^{* *}$ \\
& $(97.98)$ & $(51.46)$ & $(0.08)$ & $(4.64)$ & $(-0.60)$ & $(-6.64)$ & $(3.28)$ & $(4.60)$ \\
R square & 0.044 & 0.668 & 0.065 & 0.195 & 0.128 & 0.332 & 0.165 & 0.321 \\
\hline
\end{tabular}

Note: ${ }^{*}{ }^{* *}$ represent significance level at $5 \%$ and $1 \%$, respectively.

\subsection{The Market Reaction for the Second Adjustment}

This section shows the impact of the trading hour change in HKEx around March 5, 2012, i.e., the second adjustment. Again, we use a one-year window before and after March 5, 2012, and check the impact of the second adjustment. In the second adjustment, the trading hours are further revised from 9:30 am to 12 noon and $1 \mathrm{pm}$ to $4 \mathrm{pm}$, and the afternoon trading time is half an hour ahead, a total of 5.5 trading hours.

We first check the cumulative abnormal return around the second adjustment by adopting the same methodology as discussed above. The results of the cumulative abnormal return around the second adjustment are shown in Figure 2 and Table 4.

From Figure 2 and Table 4, we can see that there is still a negative reaction in terms of the CAR, but the magnitude is much smaller, compared with the first adjustment. It is not surprising to observe a negative market reaction, since the further extended trading hours make the brokers more depressed, but the reason why the reaction is smaller lies in the fact that, the previous year's protect does not have practical effect, and the brokers now understand that, even if they are not happy about this change, they cannot exert any de facto impact on the 


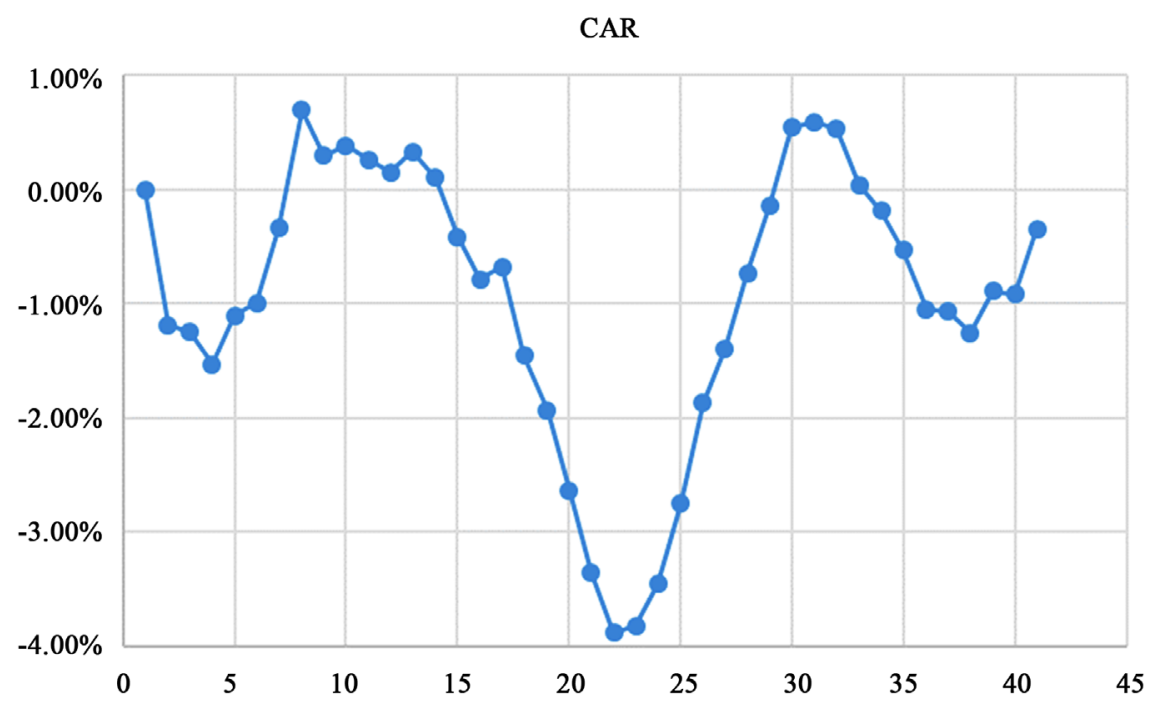

Figure 2. The cumulative abnormal return around the second adjustment.

Table 4. The cumulative abnormal return around March 5, 2012.

\begin{tabular}{ccc}
\hline Window & CAR & t-value \\
\hline$(0,1)$ & $0.00 \%$ & 0.00 \\
$(0,2)$ & $-0.18 \%$ & -4.30 \\
$(0,3)$ & $-1.25 \%$ & -4.09 \\
$(0,5)$ & $-1.10 \%$ & -3.00 \\
$(0,8)$ & $0.69 \%$ & 1.08 \\
$(0,10)$ & $0.38 \%$ & 0.49 \\
$(0,15)$ & $-0.42 \%$ & -0.53 \\
$(0,20)$ & $-2.63 \%$ & -2.38 \\
$(0,25)$ & $-2.75 \%$ & -2.33 \\
$(0,30)$ & $0.54 \%$ & 0.40 \\
$(0,35)$ & $-0.53 \%$ & -0.32 \\
$(0,40)$ & $-0.92 \%$ & -0.18 \\
\hline
\end{tabular}

adjustment. This explains why the CAR is only mildly negative for the second adjustment.

Next, we study the change of trading volume, Amihud Illiquidity, $R^{2}$ and price delay for the 60 pairs of dual-listed firms in China and Hong Kong around the second adjustment. Again, we adopt the following difference-in-difference (DID) regression model

$$
y_{i t}=\beta_{0}+\beta_{1} D_{t}+\beta_{2} D_{i}+\gamma D_{t} * D_{i}+\delta_{1} \text { Size }_{i}+\delta_{2} \text { ROA }_{i}+\delta_{3} \text { Leverage }_{i}+e_{i t}
$$

where $y_{i t}$ is the (logged) volume, Illiq, $R^{2}$, price delay, which are defined earlier. $D_{t}$ is a dummy variable which equals 1 for post-event window, and 0 for pre-event window. $D_{i}$ is a dummy variable which equals 1 if stock $i$ is a Hong Kong-listed $\mathrm{H}$-share test group, and 0 if stock $i$ is a China-listed A-share control 
group. The control variables include the logged total market capitalization of stock $i$ (Size). the return on asset for stock $i$ (ROA), and the leverage for stock $i$ in 2012. The effective date is March 5, 2012. The results are shown in Table 5.

Table 5 shows that around the second adjustment of trading hours, the interaction terms of $D_{t}^{*} D_{i}$ in all specifications of Table 5 are insignificant at $5 \%$. The results are consistent with those from the CAR, in the sense that the second adjustment of trading hours does not cause significant change in the price efficiency. First, brokers, as well as the investors, have already established the expectation after they experience the first adjustment. Second, while the first adjustment extends the trading time by one hour, the second adjustment puts only 30 minutes extra trading time. So, it is not surprising that the second adjustment does not exhibit significant impact.

\section{Conclusion}

This paper studies the impact of trading hour adjustment in Hong Kong Stock market and how this change affects the market liquidity, price synchronicity, as well as the price efficiency. We find that the extended trading hours in Hong Kong stock market result in a significantly negative cumulative abnormal return.

Table 5. Difference-in-difference Regression for the second Adjustment. This table shows the results of the DID regression. we adopt the following difference-in-difference (DID) regression model. $y_{i t}=\beta_{0}+\beta_{1} D_{t}+\beta_{2} D_{i}+\gamma D_{t} * D_{i}+\delta_{1}$ Size $_{i}+\delta_{2}$ ROA $_{i}+\delta_{3}$ Leverage $_{i}+e_{i t}$ where $y_{i t}$ is the (logged) volume, Illiq, R-square, price delay, which are defined earlier. $D_{t}$ is a dummy variable which equals 1 for post-event window, and 0 for pre-event window. $D_{i}$ is a dummy variable which equals 1 if stock $i$ is a Hong Kong-listed $\mathrm{H}$-share test group, and 0 if stock $i$ is a China-listed A-share control group. The control variables include the logged total market capitalization of stock $i$ (Size). the return on asset for stock $i$ (ROA), and the leverage for stock $i$ in 2011 .

\begin{tabular}{|c|c|c|c|c|c|c|c|c|}
\hline \multirow[b]{2}{*}{$D_{i}$} & \multicolumn{2}{|c|}{$\ln$ (Volume) } & \multicolumn{2}{|c|}{$\operatorname{ILLIQ}\left(10^{-6}\right)$} & \multicolumn{2}{|c|}{$\mathrm{R}^{\wedge} 2$} & \multicolumn{2}{|c|}{ Price delay } \\
\hline & $\begin{array}{l}-0.38 \\
(-1.51)\end{array}$ & $\begin{array}{l}-0.26 \\
(-1.79)\end{array}$ & $\begin{array}{l}1.27^{\star} \\
(2.12)\end{array}$ & $\begin{array}{l}1.09^{*} \\
(2.05)\end{array}$ & $\begin{array}{l}-0.24 \\
(-1.39)\end{array}$ & $\begin{array}{l}-0.20 \\
(-1.26)\end{array}$ & $\begin{array}{c}0.03 \\
(1.19)\end{array}$ & $\begin{array}{c}0.02 \\
(1.03)\end{array}$ \\
\hline$D_{t}$ & $\begin{array}{l}-0.15 \\
(-0.59)\end{array}$ & $\begin{array}{l}-0.02 \\
(-0.16)\end{array}$ & $\begin{array}{l}0.0265 \\
(0.04)\end{array}$ & $\begin{array}{l}-0.327 \\
(-0.61)\end{array}$ & $\begin{array}{c}0.14 \\
(0.84)\end{array}$ & $\begin{array}{c}0.17 \\
(1.09)\end{array}$ & $\begin{array}{l}0.05^{*} \\
(1.99)\end{array}$ & $\begin{array}{c}0.03 \\
(1.53)\end{array}$ \\
\hline$D_{t}^{*} D_{i}$ & $\begin{array}{c}0.15 \\
(0.42)\end{array}$ & $\begin{array}{c}0.19 \\
(0.95)\end{array}$ & $\begin{array}{l}0.489 \\
(0.58)\end{array}$ & $\begin{array}{l}0.428 \\
(0.56)\end{array}$ & $\begin{array}{c}0.14 \\
(0.84)\end{array}$ & $\begin{array}{c}0.15 \\
(0.66)\end{array}$ & $\begin{array}{c}0.06 \\
(1.72)\end{array}$ & $\begin{array}{c}0.05 \\
(1.85)\end{array}$ \\
\hline Size & & $\begin{array}{l}0.59^{* *} \\
(18.21)\end{array}$ & & $\begin{array}{c}-0.791^{* *} \\
(-6.63)\end{array}$ & & $\begin{array}{l}0.25^{\star *} \\
(7.04)\end{array}$ & & $\begin{array}{l}-0.02^{* *} \\
(-6.44)\end{array}$ \\
\hline ROA & & $\begin{array}{l}-0.04^{\star *} \\
(-2.86)\end{array}$ & & $\begin{array}{l}-0.064 \\
(-1.15)\end{array}$ & & $\begin{array}{l}-0.04^{* *} \\
(-2.58)\end{array}$ & & $\begin{array}{l}-0.004 \\
(-1.73)\end{array}$ \\
\hline Leverage & & $\begin{array}{c}0.30 \\
(0.95)\end{array}$ & & $\begin{array}{l}-0.612 \\
(-0.53)\end{array}$ & & $\begin{array}{l}-0.59 \\
(-1.75)\end{array}$ & & $\begin{array}{l}-0.06 \\
(-1.36)\end{array}$ \\
\hline Con & $\begin{array}{c}16.38 \\
(93.28)\end{array}$ & $\begin{array}{c}12.61 \\
(48.40)\end{array}$ & $\begin{array}{l}0.0398 \\
(0.09)\end{array}$ & $\begin{array}{l}5.84^{* *} \\
(6.14)\end{array}$ & $\begin{array}{l}-0.23 \\
(-1.89)\end{array}$ & $\begin{array}{l}-1.23^{* *} \\
(-4.39)\end{array}$ & $\begin{array}{l}0.04^{\star *} \\
(2.54)\end{array}$ & $\begin{array}{l}0.29^{* *} \\
(5.79)\end{array}$ \\
\hline R square & 0.014 & 0.663 & 0.054 & 0.261 & 0.022 & 0.205 & 0.129 & 0.327 \\
\hline
\end{tabular}

Note: ${ }^{*}{ }^{* *}$ represent significance level at $5 \%$ and $1 \%$, respectively. 
Also, the stock price synchronicity and the price delay all decreased significantly, which represents the improvement of the price efficiency of Hong Kong stocks.

\section{Conflicts of Interest}

The authors declare no conflicts of interest regarding the publication of this paper.

\section{References}

[1] Amihud, Y. (2002) Illiquidity and Stock Returns: Cross-Section and Time-Series Effects. Journal of Financial Markets, 5, 31-56. https://doi.org/10.1016/S1386-4181(01)00024-6

[2] Morck, R., Yeung, B. and Yu, W. (2000) The Information Content of Stock Markets: Why Do Emerging Markets Have Synchronous Stock Price Movements? Journal of Financial Economics, 58, 215-260.

[3] Wurgler, J. (2000) Financial Markets and the Allocation of Capital. Journal of Financial Economics, 58, 187-214. https://doi.org/10.1016/S0304-405X(00)00070-2

[4] Durnev, A., Morck, R. and Yeung, B. (2004) Value-Enhancing Capital Budgeting and Firm-specific Stock Return Variation. The Journal of Finance, 59, 65-105. https://doi.org/10.1111/j.1540-6261.2004.00627.x

[5] Li, K.R., Morck, R. and Yang, F. (2004) Firm-Specific Variation and Openness in Emerging Markets. Review of Economics and Statistics, 86, 658-669. https://doi.org/10.1162/0034653041811789

[6] Jin, L. and Myers, S.C. (2004) $\mathrm{R}^{2}$ around the World: New Theory and New Tests. Journal of Financial Economics, 79, 257-292. https://doi.org/10.3386/w10453

[7] Morck, R., Yeung, B. and Yu, W. (2013) R ${ }^{2}$ and the Economy. Annual Review of Financial Economy, 5, 143-166.

https://doi.org/10.1146/annurev-financial-110112-120936

[8] Hou, K. and Moskowitz, T. (2005) Market Frictions, 2005, Price Delay, and the Cross-Section of Expected Returns. Review of Financial Studies, 18, 981-1020. https://doi.org/10.1093/rfs/hhi023

[9] Merton, R. (1987) A Simple Model of Capital Market Equilibrium with Incomplete Information. Journal of Finance, 42, 483-510. https://doi.org/10.1111/j.1540-6261.1987.tb04565.x

[10] Hirshleifer, D. (1988) Residual Risk, Trading Costs, and Commodity Futures Risk Premia. Review of Financial Studies, 1, 173-193. https://doi.org/10.1093/rfs/1.2.173

[11] Coval, J.D. and Moskowitz, T. (2001) The Geography of Investment: Informed Trading and Asset Prices. Journal of Political Economy, 109, 811-841. https://doi.org/10.1086/322088

[12] Miller, E. (1977) Risk, Uncertainty and Divergence of Opinion. Journal of Finance, 32, 1151-1168. https://doi.org/10.1111/j.1540-6261.1977.tb03317.x 